\title{
Failed carotid artery stenting followed by successful surgical intervention: Case report
}

\author{
Başarısız karotis arter stentleme sonrasında başarılı cerrahi girişim: Olgu sunumu

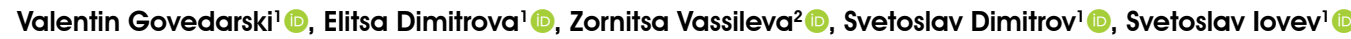 \\ 'Department of Vascular Surgery, University Hospital Saint Ekaterina, Sofia, Bulgaria \\ ${ }^{2}$ Department of Pediatric Cardiology, University National Heart Hospital, Sofia, Bulgaria
}

\begin{abstract}
A 56-year-old female patient with significant carotid stenoses with circumferential plaques, causing localized vascular narrowing, was inappropriately indicated for carotid artery stenting. After placement of a distal embolic protection device in the left internal carotid artery, a stent was inserted; however, it could not be fully deployed due to the rigid, severely calcified vascular walls. The various endovascular attempts to recapture the protection device were futile and, eventually, led to fracture of the guidewire of the device and it remained entrapped together with the stent. Emergency carotid arteriotomy with extirpation of the stent and embolic protection device via carotid thromboendarterectomy was performed. In conclusion, the proper patient selection for carotid artery stenting is of utmost importance.
\end{abstract}

Keywords: Carotid artery stenting, carotid endarterectomy, carotid stenosis, embolic protection device.

Despite the rapid development of carotid artery stenting (CAS) in recent years, the gold standard for carotid artery disease (CAD) treatment is still carotid endarterectomy (CEA), as it is feasible for both different types of plaque morphology and for anatomical variations of the carotid arteries. ${ }^{[1]}$ The appropriate indication for CAS or CEA is the most important factor to achieve favorable outcomes.

Herein, we report a case of failed CAS with need for subsequent emergency CEA, due to improper patient indication.

\section{$\ddot{O} Z$}

Damarlarda lokal daralmaya neden olan çevresel plaklar ile birlikte ciddi karotis darlıklı 56 yaşında kadın hastaya uygun olmayacak bir şekilde karotis arter stentleme yapıldı. Distal emboli koruma cihazı sol internal karotis artere yerleştirildikten sonra, stentleme yapıldı; ancak sert, ciddi düzeyde kalsifiye damar duvarları nedeniyle stent tam olarak yerleştirilemedi. Koruma cihazını tekrar yakalamak için yapılan çeşitli endovasküler girişimler sonuçsuz kaldı ve nihayetinde cihazın kılavuz telinin kırılmasına yol açarak, stent ile birlikte sıkıştı. Stentin ve emboli koruma cihazının karotis tromboendarterektomi ile çıkarılması için acil karotis arteriyotomi yapıldı. Sonuç olarak, koroner arter stentleme için doğru hasta seçimi çok önemlidir.

Anahtar sözcuikler: Karotis arter stentleme, karotis endarterektomi, karotis darlığı, emoli koruma cihazı.

\section{CASE REPORT}

A 56-year-old female smoker with arterial hypertension, dyslipidemia, and a history of CAS presented with symptoms of transient ischemic attack (three episodes within the past three months) and amaurosis fugax in the left eye (three episodes). She was on dual antiplatelet therapy (DAPT) plus statin. On Doppler ultrasonography (DUS), severely calcified circumferential plaques in both internal carotid arteries (ICAs) were detected with a peak systolic velocity of $250 \mathrm{~cm} / \mathrm{sec}$, corresponding to $>70 \%$ stenosis. ${ }^{[2]}$ After

Received: December 03, 2020 Accepted: February 06, 2021 Published online: April 26, 2021

Correspondence: Zornitsa Vassileva, MD. Department of Pediatric Cardiology, University National Heart Hospital, Str. 65, 1309 Sofia, Bulgaria. Tel: 00359898319361 e-mail: drvass@abv.bg 
vascular surgery consultation, the patient was indicated for operative treatment. A written informed consent was obtained.

The diagnostic coronarography revealed a patent coronary stent in the left anterior descending artery. On selective carotid computed tomography (CT) angiography, high-grade bilateral stenoses of both ICAs with circumferential calcified plaques, narrowing the lumen with $80 \%$ were detected. The invasive cardiologists made a unilateral decision to undertake CAS. The procedure took place one week later at the cardiology department. Through standard right femoral access, a 6-Fr sheath was inserted and aortic arch angiography was performed, followed by selective cannulation of the left common carotid artery (CCA) (Figure 1a). Using a 0.014-inch guidewire, the distal SpiderFX (ev3, Inc., MN, USA) embolic protection device (EPD) was successfully delivered and positioned

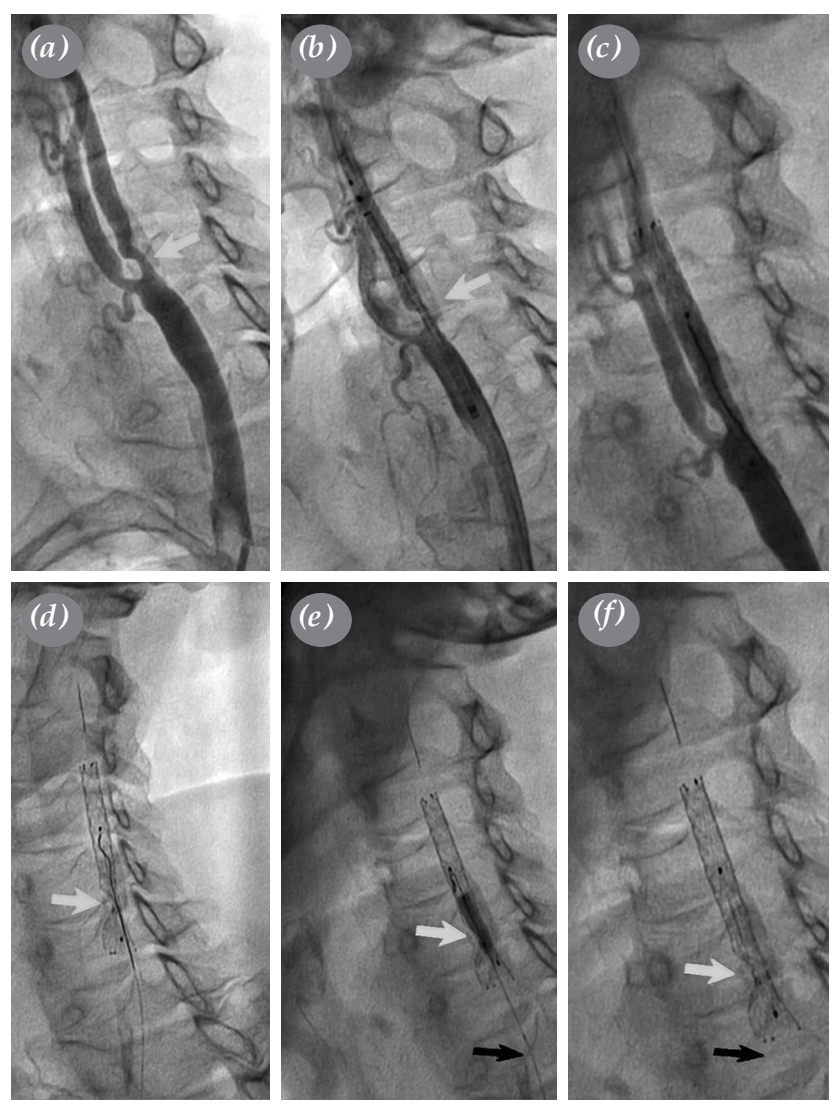

Figure 1. (a) Diagnostic angiography demonstrating severe irregular stenoses of left ICA. (b) The stent (white arrow) was introduced at the location of stenosis before its deployment (c) Stent deployment at the location of narrowing (d) The stent could not be fully deployed. (e) Balloon dilation trial to retrieve EPD. The proximal end of guidewire is visible (black arrow). (f) The broken guidewire of device, the EPD was entrapped.

ICA: Internal carotid artery; EPD: Embolic protection device. in the distal left ICA and, then, the Protégé ${ }^{\mathrm{TM}}$ stent (Covidien, Irvine, CA, USA), $8 / 6 / 40 \mathrm{~mm}$ in size, was inserted into the lesion (Figure 1b, 1c). Due to severe calcifications of the left ICA, full deployment of the stent to withdraw the EPD was not possible (Figure 1d).

The various maneuvers for EPD removal, under maximal heparinization, were futile and led to fracture of the guidewire. As a result, the device together with the undeployed stent remained entrapped at the place of insertion in the carotid artery (Figure 1e, 1f). On control angiography, the blood flow through the stent and the device was demonstrated without migration of the EPD.

Emergency surgery was decided. The left-sided CCA and its bifurcation were exposed through typical access. The ICA was followed maximally in the cranial direction, by medically controlled hypertension to ensure a better contralateral cerebral perfusion. After proximal and distal clamping of the ICA, there was no reduction of the blood flow on transcranial DUS monitoring. Longitudinal arteriotomy along the course of the stent was performed (Figure 2a). The stent with the distal protection device were extirpated en bloc (Figure 2b-d), followed by thromboendarterectomy and removal of the calcified plaques with fixation of the intima. As the elongation of the left ICA was not considered significant intraoperatively, reimplantation was not necessary. Primary closure of the arteriotomy with polypropylene $7 / 0$ was performed. The total clamping time was $20 \mathrm{~min}$.

Although the patient was on DAPT and open surgery under systemic heparinization is associated with an increased bleeding risk, we did not encounter any hemorrhagic complications. After the procedure, the DAPT was continued. On the control CT angiography on the second postoperative day, the lack of residual stenosis and non-significant elongation of the left ICA (Figure 3b) at the level of C7 were demonstrated with contralateral $80 \%$ stenosis and elongation of the right ICA (Figure 3a). Additionally, stenoses of the vertebral arteries were visualized-ostial occlusion on the left side and high-grade stenosis on the right side (Figure 3c). The right subclavian artery had 65 to $70 \%$ ostial stenosis, as well.

The patient was discharged on the third postoperative day without any neurological deficit. During the follow-up examination at one month, she had no recurrence of the preoperative neurological symptoms and was still on DAPT and statin. During the one-year postoperative follow-up with DUS every three months, the patient did not report any significant 

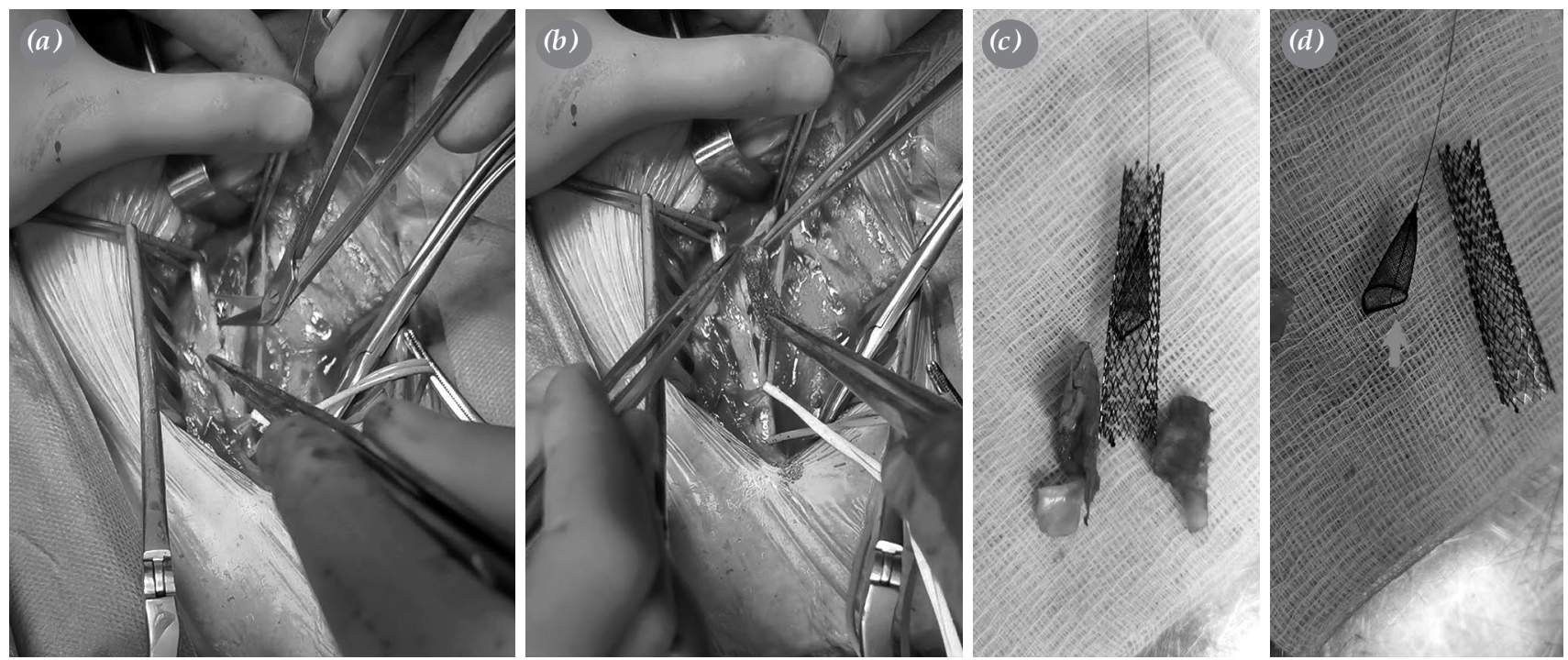

Figure 2. (a) Longitudinal arteriotomy of ICA, the stent comes into sight. (b) The extirpation of stent together with EPD. (c) The stent with EPD in it together with the removed calcified plaques. (d) The device and stent were separated, and the broken end of the guidewire is visible-arrow.

ICA: Internal carotid artery; EPD: Embolic protection device.
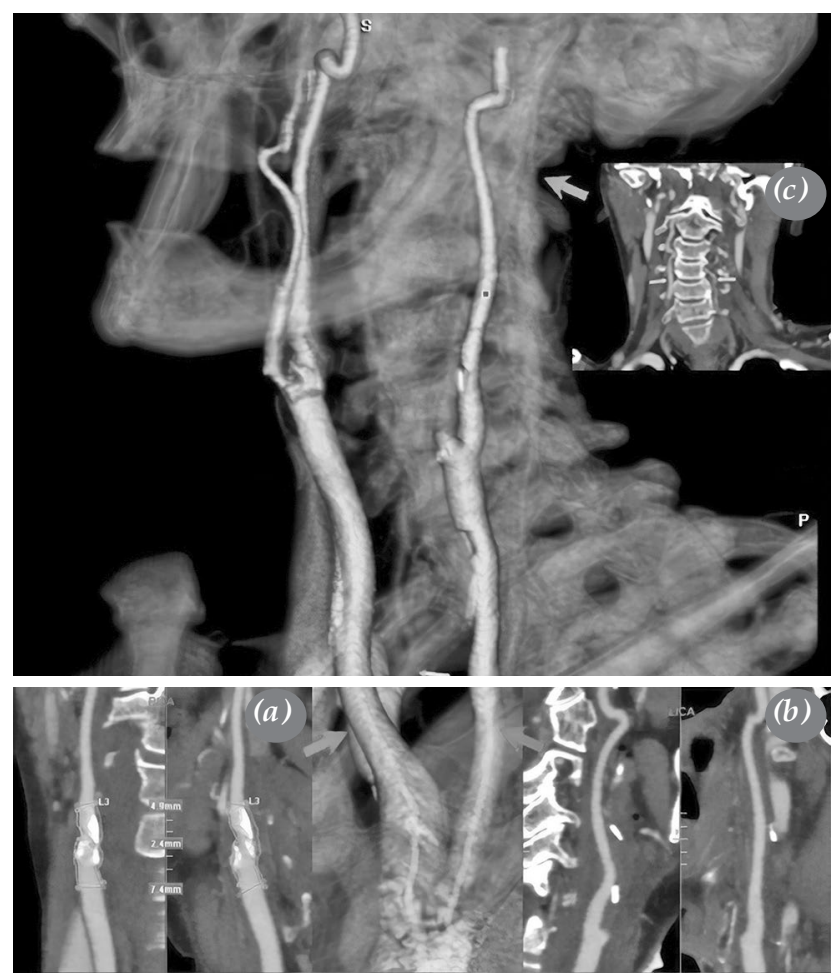

Figure 3. (a) High-grade stenosis of right ICA with circumferential stenosis (not operated). (b) Normally contrasted left ICA after surgery. (c) Stenosis of vertebral arteries.

ICA: Internal carotid artery. neurological symptoms. Neither residual stenosis of the left ICA, nor progression of the stenosis of the right ICA were documented. The multifocal atherosclerosis was an indication for subsequent operative treatment; however, the patient refused surgery.

\section{DISCUSSION}

According to the recent guidelines of the 2017 European Society of Vascular Surgery (ESVS), ${ }^{[3]}$ the indications for the most suitable therapeutic approach by the individual patient - CEA or CAS - should be assessed by a multidisciplinary team including a neurologist, vascular surgeon, and interventionalist, and the treatment decision should be made by at least two specialists (Class $1 \mathrm{C}$ recommendation). The recommendations of the ESVS state that symptomatic patients with high-grade carotid stenoses are indicated for thromboendarterectomy (Class 1A recommendation). Carotid artery stenting should be considered for by high-risk patients with significant comorbidities (Class 2B recommendation). The guidelines of the Society of Vascular Surgery (SVS) for CAD are also similar and state that CAS should be reserved for symptomatic patients with 50 to $99 \%$ stenosis who are at a high risk for CEA for anatomic or medical reasons. ${ }^{[4]}$ In accordance 
with these guidelines, the present case was indicated for CEA, but not for CAS: symptomatic patient with circumferential heavy calcification who was not high-risk for surgery.

While assessing the suitability for CAS, it is of crucial importance to avoid tortuous anatomy, heavily calcified plaques, and critically stenotic lesions to improve the success rate of CAS and to reduce the incidence of retained intraluminal devices. ${ }^{[5]}$ In most reported cases of retained EPD, the factors which are associated with a higher incidence of this complication are the severity of stenosis and the morphology of the plaque. ${ }^{[6]}$ Furthermore, the quality of the device and the technical skills of the operator are of great importance. ${ }^{[7]}$ For significant carotid stenoses, combined with arterial elongation and calcification of the plaques, CEA is a treatment method with proven efficacy. The CEA has the following advantages over CAS: solving both the stenosis and the elongation in one stage, direct and controlled embolization prevention through the use of clamping, and the established sequence of releasing retrograde and antegrade blood flow.

In conclusion, the importance of proper patient selection for CAS cannot be overemphasized. The role of the vascular surgeon in determining the feasibility of CAS is crucial, as the surgeon is the specialist who has to handle the potential complications, as demonstrated in our case. The present case did not suffer from any neurological sequelae, thanks to the timely surgical intervention.

\section{Acknowledgements}

We thank Eniko Enikov for his valuable contribution to the image editing.

\section{Declaration of conflicting interests}

The authors declared no conflicts of interest with respect to the authorship and/or publication of this article.

\section{Funding}

The authors received no financial support for the research and/or authorship of this article.

\section{REFERENCES}

1. Abdo Elhindawy KM, Ismail OA, Eldien MT. Carotid artery stenting in high-risk patients: Immediate and short-term results. Egypt J Surg 2020;39:305-12.

2. Grant EG, Benson CB, Moneta GL, Alexandrov AV, Baker JD, Bluth EI, et al. Carotid artery stenosis: Gray-scale and Doppler US diagnosis--Society of Radiologists in Ultrasound Consensus Conference. Radiology 2003;229:340-6.

3. Naylor AR, Ricco JB, de Borst GJ, Debus S, de Haro J, Halliday A, et al. Editor's choice - management of atherosclerotic carotid and vertebral artery disease: 2017 clinical practice guidelines of the European Society for Vascular Surgery (ESVS). Eur J Vasc Endovasc Surg 2018;55:3-81.

4. Ricotta JJ, Aburahma A, Ascher E, Eskandari M, Faries P, Lal BK; Society for Vascular Surgery. Updated Society for Vascular Surgery guidelines for management of extracranial carotid disease: Executive summary. J Vasc Surg 2011;54:832-6.

5. Page P, Niemann D, Son C, Li Y. Retained distal protection device during carotid artery stenting necessitating carotid endarterectomy: A complication and management considerations. Surg Neurol Int 2018;9:123.

6. Ling AJ, Mwipatayi P, Gandhi T, Sieunarine K. Stenting for carotid artery stenosis: fractures, proposed etiology and the need of surveillance. J Vasc Surg 2008;47:1220-26.

7. Coppi G, Moratto R, Veronesi J, Nicolosi E, Silingardi R. Carotid artery stent fracture identification and clinical relevance. J Vasc Surg 2010;51:1397-405. 